54888

\title{
Manipulating Subsurface Colloids to Enhance Cleanup of DOE Waste Sites
}

March 15, 2000

Philip M. Gschwend and Carol R. Johnson

MIT, 48-415, Cambridge, MA 02139

tel.617-253-1638 fax 617-253-7395 email pmgschwe@mit.edu

with

Nikolaos P. Nikolaidis and Lucas A. Hellerich

Univ. of Connecticut, Storrs, CT 06269

tel. $860-486-5648$

Two graduate students and one postdoctoral associate worked on this project.

\section{Specific DOE Problem Addressed}

Many DOE sites are polluted below ground with chemicals that cannot be readily pumped to the surface for treatment because those compounds associate too extensively with the immobile aquifer solids (Fig. 1a.) We are have been working to address this problem by using colloid mobilization to enable pumping the sorbents themselves out of contaminated subsurface sites (Fig. 1b.) To pump such colloidal sorbents out of contaminated subsurface sites, we must cause them to detach from the framework grains. Our experience indicates that this can often be done if the groundwater solution chemistry is suitably modified to (1) reverse the surface charges of key phases like amorphous iron oxyhydroxides, and (2) push the adjacent attached fines apart using electrostatic repulsions and expanded diffuse double layers.

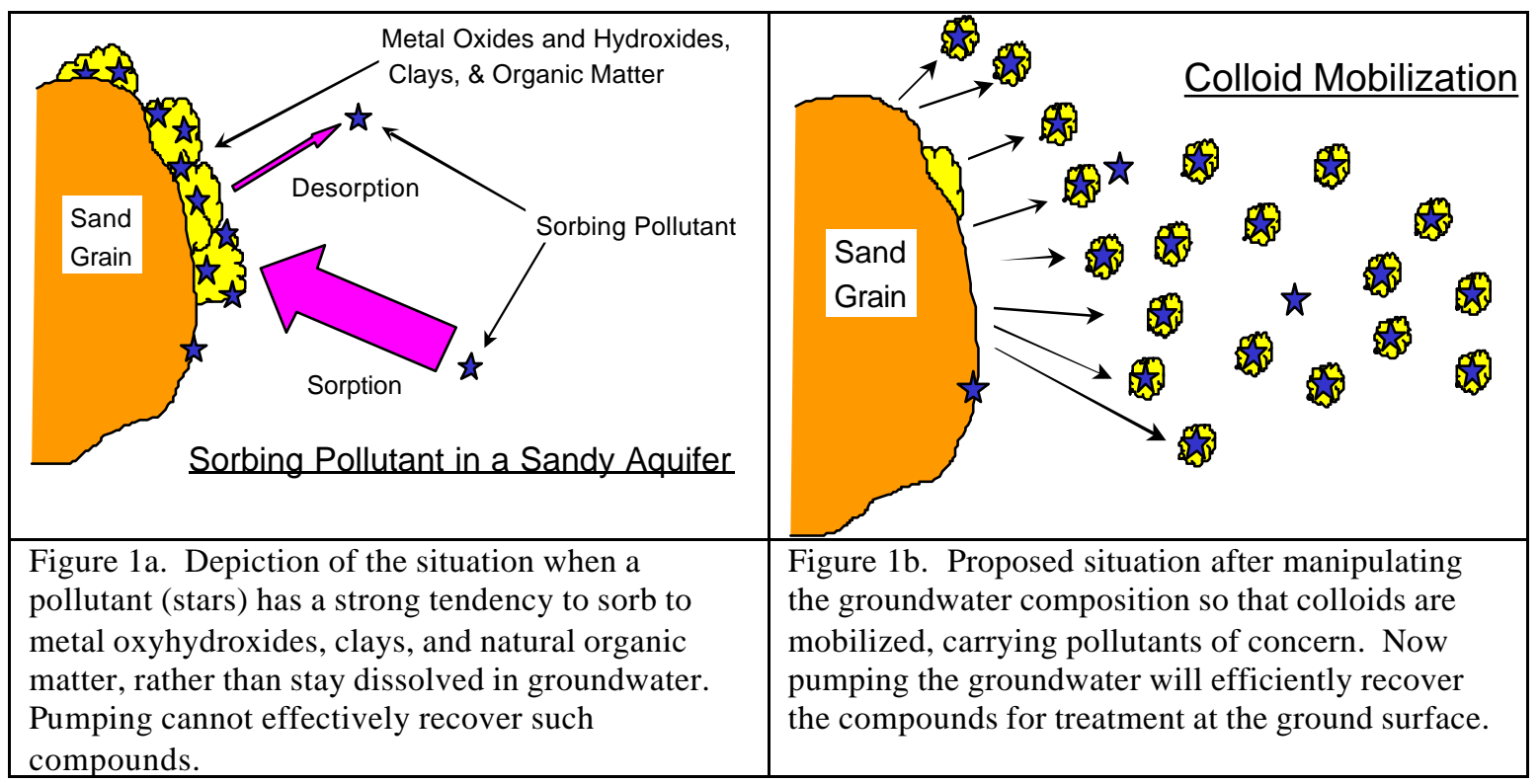




\section{Research Objective}

This project sought to: (1) understand the forces which immobilize colloids in aquifers, (2) devise aqueous solutions which disrupt these forces, and (3) test the effectiveness of colloid mobilization as a technique for removing colloids from the aquifer.

\section{Research Progress and Implications}

We have demonstrated the feasibility of groundwater manipulations to cause colloid mobilizations at two field sites, Georgetown, SC (a clean coastal plain aquifer site with geology similar to DOE's Savannah River Site) and Putnam, CT (a glacial outwash aquifer that is heavily contaminated with chromium-plating wastes.) In these two cases, we characterized the subsurface mineralogy and geochemistry, proposed and tested specific sorbate amendments in the laboratory for their effectiveness at releasing colloids from the sites' solids, and then used a novel injection-withdrawal methodology to interrogate several positions at each of the two field sites for our ability to mobilize the colloids in the field. At both sites we achieved substantial success insofar as we could cause colloidal suspensions near $100 \mathrm{mg} / \mathrm{L}$ to be pumped from below ground (Fig. 2.) In addition, we found that designing injection solutions that optimally mobilize colloids in the field also promotes desorption processes. As an example, in manipulating chromiumcontaining colloids, we found that much of our injected sorbate also served to displace the ion exchangeable chromate load in that subsurface region (Fig. 3.)

\begin{tabular}{|l|l|l|l|}
\hline \multicolumn{1}{c|}{$\begin{array}{c}\text { Experiment Two } \\
\text { Turbidity vs Volume Withdrawn }\end{array}$} \\
\hline $\begin{array}{l}\text { Figure. 2. Mobilization of colloids at the Cr- } \\
\text { contaminated site in Connecticut using 5 mM citrate } \\
\text { solution. }\end{array}$ & $\begin{array}{l}\text { Figure 3. Recovery of chromium after injecting 5 mM } \\
\text { citrate solution into Cr-contaminated site in Connecticut. }\end{array}$ \\
\hline
\end{tabular}

\section{Planned Activites}

No further laboratory or field activities are planned as our funding has ended. We will continue to pursue publication of two papers, currently in preparation: Hellerich, L.A., N.P. Nikolaidis, C.R. Johnson, and P.M. Gschwend. Bromide transport in a small-scale injection-withdrawal experiment.

Johnson, C.R., L.A. Hellerich, N.P. Nikolaidis, and P.M. Gschwend. Manipulating subsurface colloids by citrate addition to a chromium-contaminated aquifer. 